\title{
ENSAIO \\ Direitos Humanos: uma conquista civilizatória
}

\author{
Gilmar Antonio Bedin \\ Doutor em Direito do Estado pela UFSC. Professor permanente dos Programas de Pós-Graduação \\ em Direito da Unijuí e da URI - Santo Ângelo. gilmarb@unijui.edu.br

\section{Giuseppe Tosi}

Doutor em Filosofia pela Universidade de Pádua e pós-doutor em Teoria e História do Direito pela Universidade de Firenze e na Universidade de Camerino. Professor da Universidade Federal da Paraíba (UFPB). pinuccio@uol.com.br

\begin{abstract}
Recebido em: 16/10/2018
\end{abstract}
Aceito em: 23/10/2018

O tema dos Direitos Humanos já possui uma longa tradição histórica (de praticamente 250 anos). Esse sistema de proteção, no entanto, enfrenta, ainda hoje, grandes controvérsias. É que alguns, politicamente mais à esquerda, afirmam que os Direitos Humanos são apenas direitos burgueses e que, portanto, não protegem os grupos mais pobres da população e nem eliminam a exploração capitalista. Outros, politicamente mais à direita, dizem, por sua vez, que "os Direitos Humanos somente defendem bandidos, que os Direitos Humanos somente defendem quem não presta". Em consequência, defendem que os Direitos Humanos somente deveriam valer para os que consideram "humanos direitos". Será que isso é verdade ou é mentira? É mito ou realidade?Para responder, vamos ver mais de perto o que são os Direitos Humanos. Os Direitos Humanos não são de esquerda ou de direita; são os alicerces do Estado de Direito e da nossa Constituição atual (artigos 5 a 17으). Além disso, não deve ser esquecido que os Direitos Humanos constituem um padrão mínimo de uma proposta de convivência humana mais civilizada. Dito de outra forma, é justamente os Direitos Humanos que nos retiram da barbárie típica do estado de natureza. Sem os Direitos Humanos a sociedade vira uma selva e a convivência humana uma guerra de todos contra todos. Os Direitos Humanos, portanto, são uma das formas de produção de paz social.

Os Direitos Humanos defendem os direitos de todos e possuem conteúdos muito distintos. De fato, os Direitos Humanos abrangem várias gerações, formando uma narrativa em expansão. Em primeiro lugar temos os direitos civis (direito de ir e vir, direito à vida, à liberdade de expressão, a um julgamento justo); em segundo lugar os direitos políticos (direito de votar e ser votado); em terceiro lugar temos os direitos econômicos e sociais (direito à educação, ao trabalho, à previdência social). Além disso, podemos também falar dos direitos na sociedade internacional. O certo é que essas várias gerações formam uma grande corrente de proteção de todos, sem distinção de raça, sexo, tendências políticas, ideológicas ou religiosas.

Por isso, é possível esclarecer que os Direitos Humanos defendem muitos aspectos da convivência humana.

Os Direitos Humanos defendem o ensino público universal e gratuito como uma das principais ferramentas de ascensão social, para formar pessoas para o mercado de trabalho e cidadãos conscientes dos seus direitos e deveres, educando-os para a tolerância, a solidariedade, a paz e os valores democráticos. A educação em e para os Direitos Humanos deve ser a base de toda a formação, desde o Ensino Fundamental até o Ensino Superior, como determina o Conselho Nacional de Educação. 
Os Direitos Humanos defendem os direitos de todos os trabalhadores a um trabalho digno e decente, contra as condições de trabalho e de salário aviltantes e indignas e semelhantes à escravidão.

Os Direitos Humanos defendem os direitos das mulheres à vida, ao trabalho, à saúde, à educação e à paridade de tratamento no trabalho, na família e na sociedade. Os Direitos Humanos são contra o feminicídio, a violência doméstica, o assédio sexual e todas as formas de violência e de discriminação contra as mulheres.

Os Direitos Humanos defendem os direitos de a população LGBTI viver livremente a própria sexualidade ou orientação sexual, que não é uma opção, mas uma condição de vida que sempre existiu e que deve ser respeitada; são contra o assassinato e a violência contra homossexuais, lésbicas, travestis, transgêneros.Os Direitos Humanos defendem a liberdade de religião dentro de um Estado laico. O Estado não tem religião; a religião é um assunto privado; as igrejas devem respeitar as leis do Estado e não podem perseguir outras religiões ou impor suas ideias e comportamentos às outras religiões ou a quem não as tem. Os Direitos Humanos defendem a tolerância religiosa como uma grande conquista civilizatória da humanidade contra o fanatismo e o fundamentalismo religioso.

Os Direitos Humanos defendem a justiça pública e não a vingança privada, como um grande avanço civilizacional desde os tempos dos antigos códigos de Lei: por isso, os cidadãos andam sem armas e entregam ao Estado e aos profissionais da segurança este direito/ dever. Por isso, os Direitos Humanos defendem os policiais, porque a polícia é defensora dos Direitos Humanos; defende a vida, a liberdade, a propriedade, o direito de ir e vir de todos os cidadãos. É um absurdo colocar a polícia contra os Direitos Humanos. O direito à segurança é um direito fundamental, e a polícia, assim como a sociedade, é responsável por esse direito, como afirma a Constituição.

Nesse contexto, os Direitos Humanos defendem melhores condições de vida e de trabalho para os policiais e defendem a sua vida: se o policial não consegue proteger a sua vida, como pode proteger a dos cidadãos?! O assassinato de policiais é o sinal dramático da falência do nosso sistema de segurança pública, que não oferece garantias mínimas nem para os cidadãos tampouco para os policiais e para os "bandidos": policial mata bandido, bandido mata policial, o cidadão fica entre o fogo cruzado e o círculo da violência continua gerando mais violência e insegurança para todos. Mais truculência e mais repressão policiais não resolvem, mas agravam a crise! Assim, dar "licença para matar" ao policial somente agrava a situação e significa que ele se torna, em poucos minutos, quem prende, julga, condena e executa a pena! Significa também aumentar o risco de reação letal por parte dos criminosos diante da abordagem policial, pois reagir será lutar pela vida.

Por outro lado, os Direitos Humanos defendem os bandidos porque o bandido perde a liberdade, mas não a dignidade, e o tratamento que recebe nas prisões e masmorras brasileiras é indigno de qualquer ser humano e não torna ninguém melhor. Os Direitos Humanos defendem um tratamento digno para os presos, com oferta de oportunidade de trabalho, de estudo e de reeducação. Deixar o sistema penitenciário como está ou aumentar ainda mais a quantidade de presos significa incentivar o crime.Os Direitos Humanos defendem os programas sociais de renda mínima e as ações afirmativas como instrumentos para permitir uma equalização das oportunidades para todos os cidadãos brasileiros, sem distinção. 
Os Direitos Humanos defendem a liberdade de ensino dos professores, dentro dos limites ditados pela lei, para eles como para todos os cidadãos, sem pressões, censuras ou intimidações. O pluralismo ideológico é a base de uma formação que respeite os outros, as diferenças.

Os Direitos Humanos defendem a família, nas suas diversas maneiras de ser, e defendem o apoio do Estado para que toda família tenha condições mínimas para crescer e educar os seus filhos, para que nenhuma família brasileira passe fome e necessidade.

Os Direitos Humanos defendem as populações indígenas e negras, e o seus territórios, culturas e identidades. Os Direitos Humanos defendem a reforma agrária por meio de uma redistribuição da terra, defendem a demarcação das terras indígenas para proteger a cultura indígena e o patrimônio natural de todos, defendem a demarcação das terras e o respeito à cultura dos quilombolas, herança da luta e da resistência dos escravos negros.

Os Direitos Humanos condenam o racismo em todas as suas formas e manifestações: só há uma raça, a humana, e diferentes etnias e culturas, que merecem respeito.

Os Direitos Humanos defendem que todo o cidadão deve ter as mesmas condições básicas de vida, moradia, alimentação, educação e saúde para poder participar em pé de igualdade com os outros no mercado de trabalho e usufruir tudo o que a sociedade the oferece. Os Direitos Humanos defendem a igualdade.

Os Direitos Humanos somente prosperam em um ambiente democrático. Não há democracia sem Direitos Humanos e não há Direitos Humanos sem democracia. Defender a democracia significa defender a vontade da maioria, mas também os direitos das minorias: sem isso a democracia se torna uma tirania da maioria sobre a minoria.

Democracia significa soberania popular, separação dos poderes, liberdade de expressão e de formação de associações e partidos, liberdade de votar e ser votado, subordinação do poder militar ao poder civil. Democracia é administração dos conflitos sem recorrer à violência, ou recorrendo à violência legítima do Estado, exercida nos limites da lei.

Os Direitos Humanos são contra as ditaduras e os Estados autoritários e totalitários, que violam os princípios básicos do Estado de Direito, promovem a tortura e consideram o adversário político um inimigo a ser exterminado.

Os Direitos Humanos defendem que o direito à informação deve ser amplo, democrático, dotando a sociedade de mecanismos de regulamentação para evitar o monopólio dos meios de comunicação, assegurando a pluralidade de manifestações de visões de mundo.

Os Direitos Humanos são contra a crescente militarização da segurança pública e de outros âmbitos das relações sociais no Brasil: o exército e a polícia têm as suas atribuições claramente determinadas pela Constituição e todos eles estão subordinados ao poder político civil. O período das ditaduras militares no Brasil e na América Latina é uma página trágica da nossa História, que deve ser definitivamente virada. Ditaduras nunca mais!

Os Direitos Humanos defendem o respeito, pelo Estado Brasileiro, do direito internacional dos Direitos Humanos; defendem os princípios do multilateralismo e da cooperação entre as nações em pé de igualdade, contra qualquer tipo de imperialismo; o respeito dos organismos internacionais de proteção dos direitos humanos da Organização das Nações Unidas, entidade que o Brasil ajudou a fundar em 1945 e o respeito aos Pactos e Protocolos In- 
ternacionais de Direitos Humanos assinados pelo Estado brasileiro, que fazem parte do direito interno. O Brasil foi um dos 48 países que participaram da elaboração e assinaram a Declaração Universal dos Direitos Humanos de 1948. O mesmo vale para para o sistema regional de proteção dos direitos humanos. É importante lembrar que esse sistema é articulado pela Organização dos Estados Americanos (OEA) e que o Brasil sempre o apoiou. O seu principal documento legal atual - a Convenção Americana de Direitos Humanos ou Pacto de São José da Costa Rica - é uma referência indiscutível.

Assim, voltando ao início da nossa conversa, é possível afirmar que os Direitos Humanos são fruto de um longo processo histórico de lutas, revoluções, guerras e conflitos que convenceram a humanidade a adotá-los como padrão civilizatório mínimo. Eles reúnem, portanto, o que há de melhor na História da civilização humana: a liberdade, a igualdade e a fraternidade.

A liberdade civil e política é a herança do liberalismo político deixada pelas revoluções burguesas contra o absolutismo monárquico e o sistema econômico feudal; a igualdade social e econômica é a herança das revoluções socialistas contra a exploração capitalista; e a fraternidade é a herança do cristianismo social, que ensina que todo ser humano é criado à imagem e semelhança de Deus e que em todos, inclusive no mais desprezível, há uma centelha divina, o que lhe confere uma dignidade própria.Os Direitos Humanos são uma secularização do cristianismo, ou seja, uma tradução, em termos laicos e racionalistas, dos princípios teológicos cristãos, como também de outras religiões do mundo inteiro. Dizer-se cristão e ser contra os Direitos Humanos é algo incompatível; pregar o Evangelho e estimular o ódio e a violência é algo incompatível; o Evangelho é uma doutrina de paz e de amor e não de ódio e de violência; o Evangelho prega o desarmamento dos corações e das mentes e o amor ao próximo (parábola do bom samaritano).

Os Direitos Humanos não são facultativos; fazem parte das obrigações éticas, jurídicas e políticas que todo cidadão brasileiro deve respeitar.

O leitor que chegou até aqui percebe, então, quanto é absurdo afirmar que "os Direitos Humanos são somente direitos burgueses", "os Direitos Humanos só defendem bandidos", que "os Direitos Humanos só valem para os humanos direitos", que "bandido bom é bandido morto", que "os Direitos Humanos só defendem quem não presta". Quantos equívocos!

Os Direitos Humanos protegem todos os cidadãos brasileiros nos seus direitos básicos e fundamentais. Por isso, eles são universais, são para todos ou para ninguém, sem exceções.

Estes princípios deveriam ser óbvios para todos e ensinados desde pequenos pela família, a escola, os partidos, os meios de comunicação. No Brasil, no entanto, há uma campanha permanente de difamação, descrédito e desinformação contra os Direitos Humanos, a ponto que em uma recente pesquisa do Instituto Ipsos sobre a percepção dos Direitos Humanos em 28 países do mundo, o Brasil está no topo da lista: é o pais onde mais de $60 \%$ da população acredita que os Direitos Humanos defendem pessoas e grupos sociais que não merecem ser protegidos.

Esse fato é fruto de uma crise econômica, política e ética de grandes proporções. É certo, porém, que, mais cedo ou mais tarde, sairemos dessa crise. O mote para a saída da crise será o fortalecimento dos Direitos Humanos (de todos) e não a relativização da constituição e da democracia. Com paz e tolerância, portanto, e não com mais ódio e violência; com mais 
justiça (para todos) e não apenas para um pequeno grupo (seja de esquerda ou de direita). É com esse fundamento que vamos construir a sociedade mais justa e solidária que o Brasil merece ser.

Essa é uma das grandes lições da História (ver a Alemanha de Hitler, a Itália de Mussolini e a União soviética de Stalin). Por isso, é importante lembrarmos que descartarmos os Direitos Humanos e a democracia somente retardará o processo de reconstrução do país e do mundo. Nesse sentido, temos de encarar as dificuldades do país (que são muitas) e identificar as suas verdadeiras causas. A defesa dos Direitos Humanos (quando é feita de forma correta) não é a causa dos problemas das sociedades atuais. É que hoje vivemos um quadro político de excesso de ideologia e de radicalismo, mas não gerados pela defesa dos Direitos Humanos e sua efetivação. Nesse sentido, é importante lembrar que Hitler culpou os judeus pelos problemas da Alemanha; o socialismo real os chamados desvios burgueses; a ditadura militar os comunistas, e agora-querem fazer dos Direitos Humanos o bode expiatório de todos os problemas do Brasil.Por isso, é fundamental termos clareza que os Direitos Humanos são apenas a concretização de uma ideia de civilização avançada e de paz por meio do direito (refletida no conceito de Estado de Direito).Assim, é importante não se deixar enganar e lembrar que a violência obscurece a nossa mente e o ódio endurece o nosso coração.

Ou Direitos Humanos ou barbárie!

João Pessoa-PB, ljuí-RS, 5 de outubro de 2018 